\title{
IDENTIFIKASI STRUKTUR BAWAH PERMUKAAN DI SEKITAR MANIFESTASI PANASBUMI REATOA KABUPATEN MAROS MENGGUNAKAN SURVEI GEOLISTRIK RESISTIVITAS
}

\author{
Nur Ayu Anas*, Syamsuddin, Bambang Harimei, Muhammad Nasri \\ Laboratorium Geofisika Padat, Departemen Geofisika, Fakultas Matematika dan Ilmu Pengetahuan Alam, \\ Universitas Hasanuddin, Makassar, Indonesia. \\ *Corresponding author. Email: ayuanas741@gmail.com
}

Manuscript received: 1 January 2020*); Received in revised form: 6 April 2020; Accepted: 8 April 2020

\begin{abstract}
Abstrak
Penelitian ini bertujuan untuk mengidentifikasi struktur bawah permukaan berupa rekahan pada daerah sekitar manifestasi mata air panas Reatoa di Dusun Realolo, Kabupaten Maros. Beberapa penelitian mengenai panasbumi di Sulawesi Selatan menggunakan geolistrik resistivitas pernah dilakukan untuk mencari zona aquifer hidrothermal di sekitar sumber air panas Panggo di Desa Kaloling, Kabupaten Sinjai. Penelitian ini juga pernah dilakukan dalam eksplorasi mata air panas menggunakan metode geolistrik resisitivitas di daerah Kabupaten Pinrang. Dalam penelitian ini menggunakan metode geolistrik resistivitas konfigurasi Wenner - Schlumberger sebanyak 4 lintasan. Panjang masing masing lintasan adalah $300 \mathrm{~m}$ dan jarak antar elektroda $5 \mathrm{~m}$. Hasil yang diperoleh merupakan kondisi geologi bawah permukaan daerah penelitian dengan nilai resistivitas kurang dari $8,35 \Omega \mathrm{m}$ diduga sebagai zona aquifer dan batuan yang berasosiasi dengan fluida. Nilai resistivitas $8,35 \Omega \mathrm{m}-16,7 \Omega \mathrm{m}$ diperkirakan sebagai satuan batu pasir yang berselingan dengan batulempung dan nilai resistivitas lebih dari 23,6 $\Omega \mathrm{m}$ diduga sebagai batuan breksi gunungapi dari batuan gunungapi Formasi Camba. Hasil penelitian juga menunjukkan adanya rekahan pada titik 110 - $130 \mathrm{~m}$ pada lintasan 1 dan titik $210-215$ m pada lintasan 2 yang memiliki arah sejajar dengan mata air panas Reatoa, sehingga rekahan ini diduga menjadi penyebab fluida panas yang berada pada aquifer memiliki celah ke permukaan dan membentuk manifestasi berupa mata air panas.
\end{abstract}

Kata Kunci: Geolistrik Resistivitas; Manifestasi; Mata Air Panas.

\begin{abstract}
The research aims to identify the subsurface structure in the area around the manifestation of Reatoa hot spring in Realolo Hamlet, Maros Regency. Some research on the geothermal in South Sulawesi used the resistivity of geoelectric ever done to find the aquifer zone hydrothermal around the Panggo hot springs in Kaloling village, Sinjai Regency. This research has also been conducted in hot spring exploration using the method of Geoelectric Resistivity in Pinrang County. In this study using the Geoelectric method of resistivity of the Wenner-Schlumberger configuration as much as 4 tracks. The length of each pass is $300 \mathrm{~m}$ and the distance between the electrodes is $5 \mathrm{~m}$. The result is a geological condition under the surface of the research area with a resistivity value of less than $8.35 \Omega \mathrm{m}$ is suspected to be the aquifer zone and associated rock with fluid. The resistivity value $8.35 \Omega \mathrm{m}-16.7 \Omega \mathrm{m}$ is thought to be a unit of sandstone that is cluttered with the claystone and the resistivity value of more than 23.6 $\Omega \mathrm{m}$ is suspected to be a volcanic rock of Camba Formation. The results of the study also showed that there were recitations at a point of $110-130 \mathrm{~m}$ on the lane 1 and $210-215 \mathrm{~m}$ points on the lane 2
\end{abstract}


which had a parallel direction to the hot springs of Reatoa, so that the recitation was suspected to be the cause of heat fluid that was on aquifer Have gaps to the surface and form manifestations of hot springs.

Keywords: Geoelectric Resistivity; Hot Springs; Manifestations.

\section{Pendahuluan}

Panasbumi merupakan salah satu energi terbarukan yang berasal dari dalam bumi. Salah satu daerah yang memiliki manifestasi panasbumi adalah Dusun Realolo berupa mata air panas Reatoa. Mata air panas merupakan salah satu petunjuk adanya sumber daya panas bumi di bawah permukaan. Mata air panas ini terbentuk karena adanya aliran air panas dari bawah permukaan melalui rekahanrekahan batuan (Saptadji, 2001). Penelitian ini bertujuan untuk mengidentifikasi struktur bawah permukaan berupa rekahan pada daerah sekitar manifestasi mata air panas Reatoa di Dusun Realolo, Kabupaten Maros. Beberapa penelitian mengenai panasbumi di Sulawesi Selatan menggunakan geolistrik resistivitas pernah dilakukan oleh Lantu dkk. (2015) untuk mencari zona aquifer hidrothermal di sekitar sumber air panas Panggo di Desa Kaloling, Kabupaten Sinjai. Penelitian ini juga pernah dilakukan oleh Fais (2017) dalam eksplorasi mata air panas menggunakan metode geolistrik resisitivitas di daerah Kabupaten Pinrang.

\section{Geologi Regional}

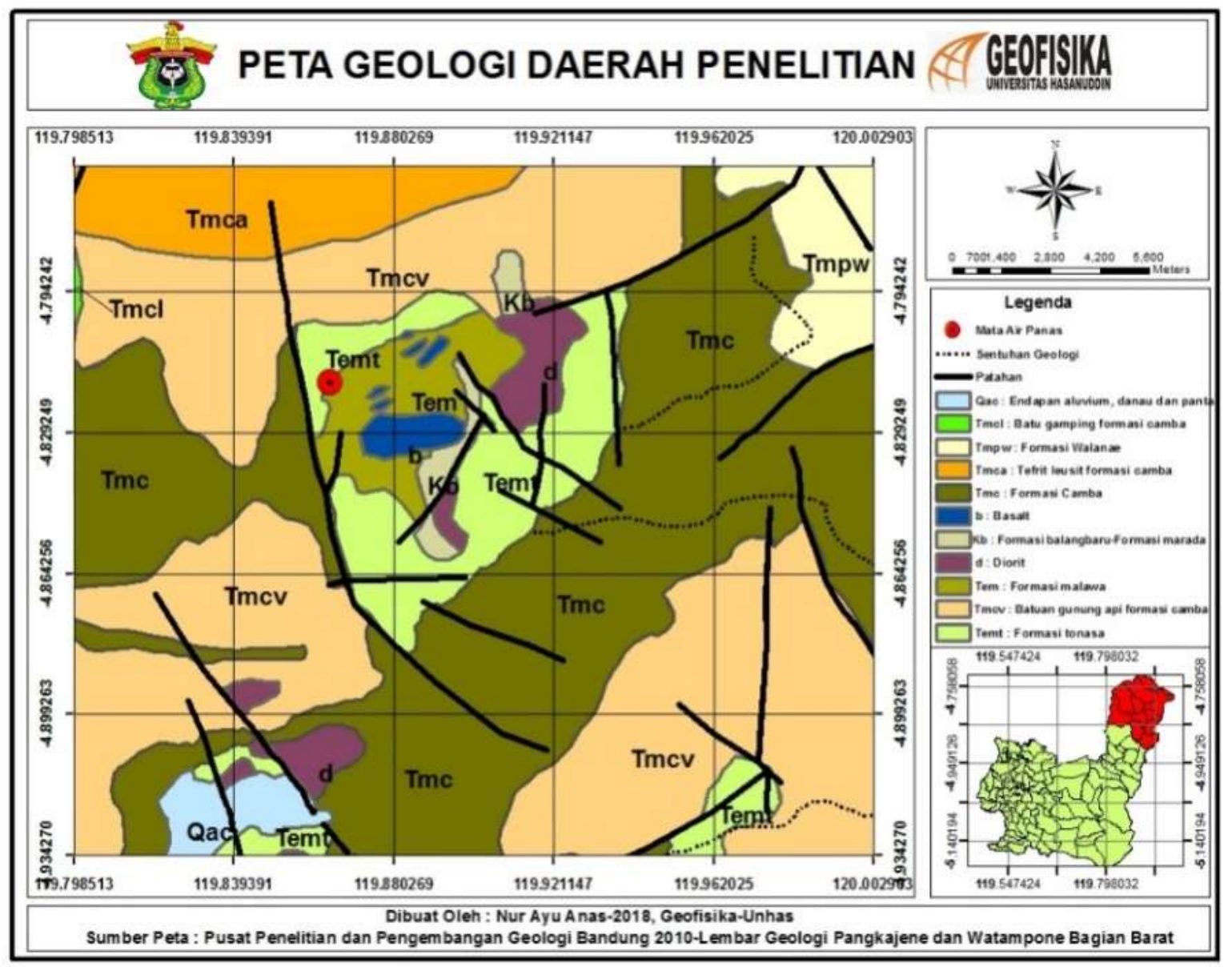

Gambar 1. Peta geologi daerah penelitian Lembar Pangkajene dan Watampone Bagian Barat (Pusat Penelitian dan Pengembangan Geologi Bandung, 2010) 
Batuan sedimen Formasi Mallawa yang sebagian besar dicirikan oleh endapan darat dengan sisipan batubara, menindih tak selaras batuan gunangapi Paleosen dan batuan flysch Kapur akhir. Pada bagian atas Formasi Mallawa ini secara berangsur beralih ke endapan karbonat Formasi Tonasa yang terbentuk secara menerus dari Eosen awal sampai bagian bawah Miosen tengah (Sukamto dan Supriatna, 1982).

Berdasarkan peta geologi daerah penelitian (Gambar 1), pada titik merah merupakan mata air panas Reatoa yang berada di daerah Mallawa. Peta geologi ini termasuk dalam Geologi Regional Lembar Pangkajene dan Watampone Bagian Barat. Mata air panas terletak di antara Formasi Mallawa (Tem), Formasi Tonasa (Temt) dan batuan gunungapi Formasi Camba (Tmcv). Formasi Mallawa (Tem) merupakan batupasir, konglomerat, batulanau, batulempung dan napal. Formasi Tonasa (Temt) merupakan batugamping koral pejal sebagian terhablurkan (Pusat Penelitian dan Pengembangan Geologi Bandung, 2010).

\section{Geolistrik Resistivitas Konfigurasi Wenner-Schlumberger}

Konfigurasi Wenner - Schlumberger merupakan gabungan antara konfigurasi Wenner dan Schlumberger. Kedalaman rata-rata pada konfigurasi ini $10 \%$ lebih besar dari konfigurasi Wenner. Konfigurasi Wenner - Schlumberger juga memiliki cakupan horizontal sedikit lebih baik dibandingkan dengan konfigurasi Wenner. Cakupan data horizontal sedikit lebih lebar dari konfigurasi Wenner (Telford et al., 1990).

Berdasarkan Gambar 2, $C_{1}$ dan $C_{2}$ adalah elektroda arus, $P_{1}$ dan $P_{2}$ adalah elektroda potensial. $a$ adalah spasi elektroda, $n$ adalah perbandingan jarak antara elektroda $C_{l}$ dan $P_{1}$. Sehingga untuk menghitung faktor geometri pada konfigurasi Wenner Schlumberger menjadi (Loke, 2004):

$k=\pi n(n+1) a$

$k$ merupakan faktor geometri yang nilainya bervariasi bergantung pada jarak dari " $a$ ".

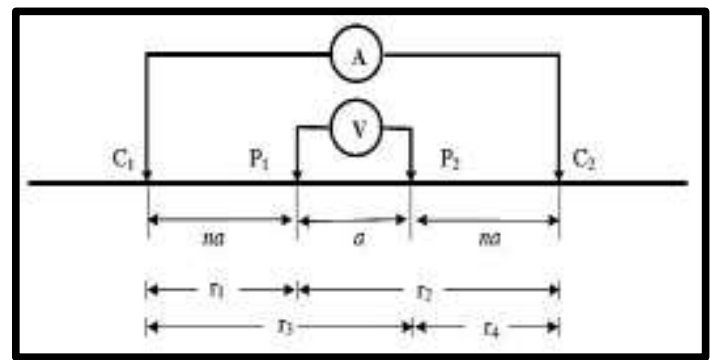

Gambar 2. Susunan elektroda konfigurasi WennerSchlumberger (Loke, 2004).

Resistivitas semu dirumuskan (Loke, 2004):

$\rho_{a}=k \frac{\Delta V}{I}$

Jika disubtitusi nilai $k$ pada persamaan (2) maka dapat dihitung nilai resistivitas semu untuk tiap kedalaman (Loke, 2004):

$\rho_{a}=\pi n(n+1) a \frac{\Delta V}{I}$

$\rho_{a}$ merupakan resistivitas semu (ohm.m), $\Delta V$ adalah beda potensial (volt) dan $I$ adalah arus (ampere). Nilai resistivitas batuan dapat dilihat pada Tabel 1 .

Tabel 1. Nilai resistivitas mineral dan batuan (Loke, 2004)

\begin{tabular}{ll}
\hline \multicolumn{1}{c}{ Material } & Resistivity $(\Omega \mathrm{m})$ \\
\hline $\begin{array}{l}\text { Igneous and Metamorphic } \\
\text { Rocks } \\
\text { Granite }\end{array}$ & \\
Basalt & $5 \times 10^{3}-10^{4}$ \\
Slate & $10^{3}-10^{6}$ \\
Marble & $6 \times 10^{2}-4 \times 10^{7}$ \\
Quartzite & $10^{2}-2.5 \times 10^{8}$ \\
Sedimentary Rocks & $10^{2}-2 \times 10^{8}$ \\
Sandstone & \\
Shale & $8-4 \times 10^{3}$ \\
Limestone & $20-2 \times 10^{3}$ \\
Soils and Waters & $50-4 \times 10^{2}$ \\
Clay & \\
\hline
\end{tabular}




\begin{tabular}{ll}
\hline Alluvium & $10-800$ \\
$\begin{array}{l}\text { Groundwater (fresh) } \\
\text { Sea water }\end{array}$ & $10-100$ \\
Chemicals & 0.2 \\
Iron & \\
O.01 M Potassium chloride & $9.074 \times 10^{-8}$ \\
O.01 M Sodium chloride & 0.708 \\
O.O1M Acetic acid & 0.843 \\
Xylene & 6.13 \\
\hline
\end{tabular}

Penelitian ini bertujuan untuk mengidentifikasi struktur bawah permukaan berupa rekahan pada daerah penelitian. Manfaat penelitian sebagai salah satu cara untuk mengetahui penyebab adanya mata air panas Reatoa di Dusun Realolo, Kecamatan Mallawa, Kabupaten Maros, Sulawesi Selatan.

\section{Metode Penelitian}

Penelitian ini dilakukan di sekitar mata air panas Reatoa, Dusun Realolo, Desa Samaenre, Kecamatan Mallawa, Kabupaten Maros. Peta lintasan pengukuran ditunjukkan pada Gambar 3.

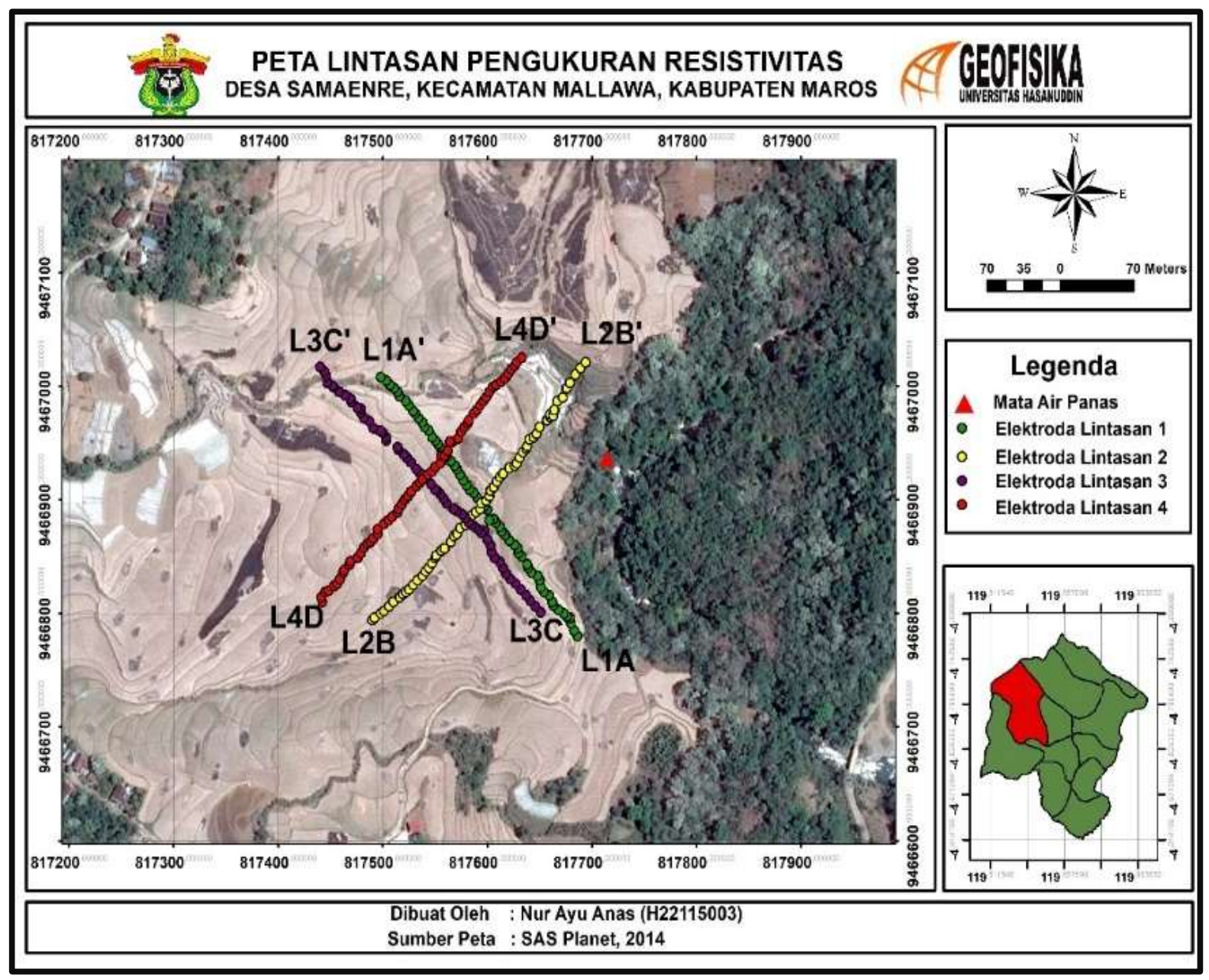

Gambar 3. Peta lintasan pengukuran (SAS Planet, 2019)

Alat yang digunakan adalah Geomative CS60. Pengukuran dilakukan dengan menggunakan konfigurasi Wenner Schlumberger. Jumlah lintasan adalah 4 dengan panjang bentangan masing masing $300 \mathrm{~m}$ dan spasi elektroda terkecil adalah $5 \mathrm{~m}$.
Data yang digunakan pada penelitian ini merupakan data primer yaitu:

1. Data geologi yang bersumber dari geologi regional Lembar Pangkajene dan Watampone Bagian Barat dan kondisi geologi di lokasi penelitian. 
2. Data lapangan yang diperoleh dari akuisisi data berupa nilai arus, potensial dan kalkulasi untuk memperoleh nilai resistivitas semu.

Pengolahan data dilakukan untuk memperoleh penampang 2D dan 3D, selanjutnya diinterpretasi dengan cara mengkorelasikannya pada data geologi serta kondisi lapangan di daerah penelitian.

\section{Hasil Dan Pembahasan}

Hasil pengolahan data berupa penampang resistivitas $2 \mathrm{D}$ yang telah diinversi dan dibagi menjadi tiga bagian yaitu low resistivity $(<8,35 \Omega \mathrm{m})$, medium resisitivity $(8,35 \Omega \mathrm{m}-16,7 \Omega \mathrm{m})$, dan high resistivity (> 23,6 $\Omega \mathrm{m}$ ). Data inversi yang diperoleh kemudian diekspor untuk membuat penampang 3D. Hasil penampang 2D dan 3D ditunjukkan pada Gambar 4 - 9 yang kemudian diinterpretasi.

\section{Penampang 2D}

\section{Lintasan 1}

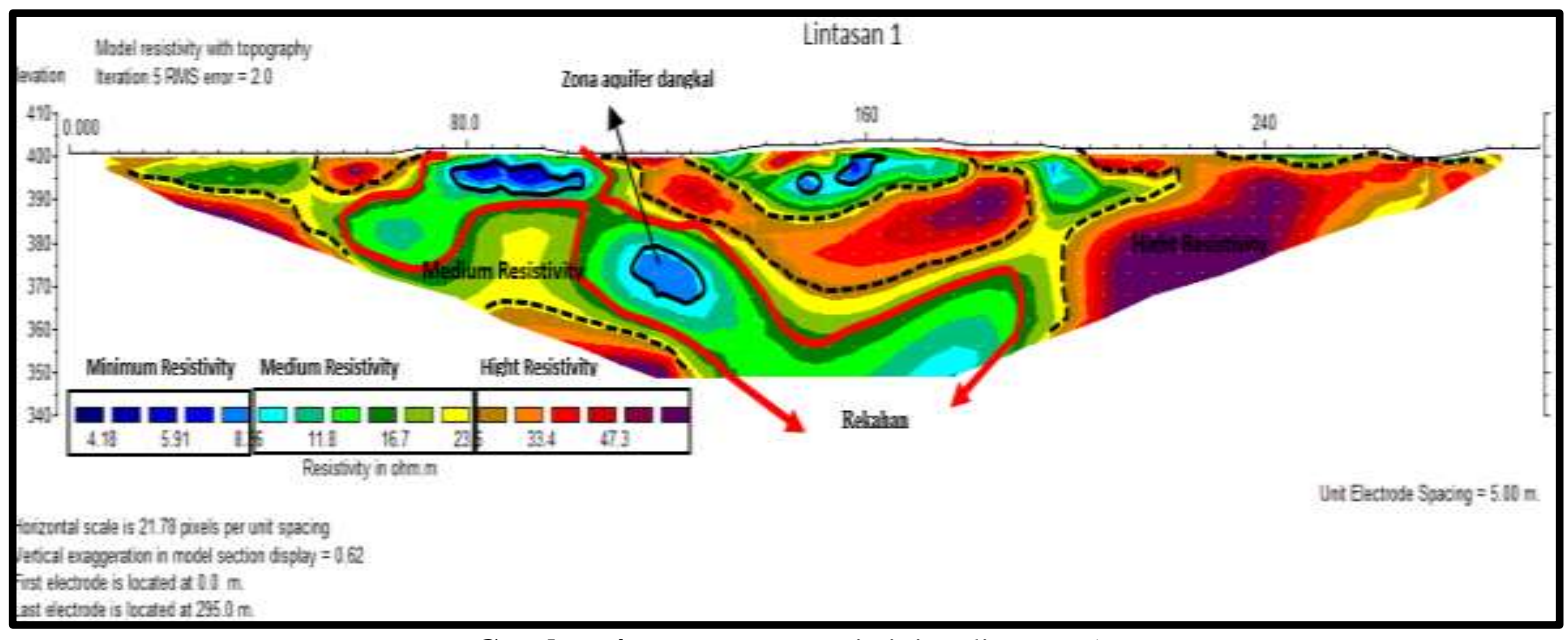

Gambar 4. Penampang resistivitas lintasan 1

\section{Lintasan 2}

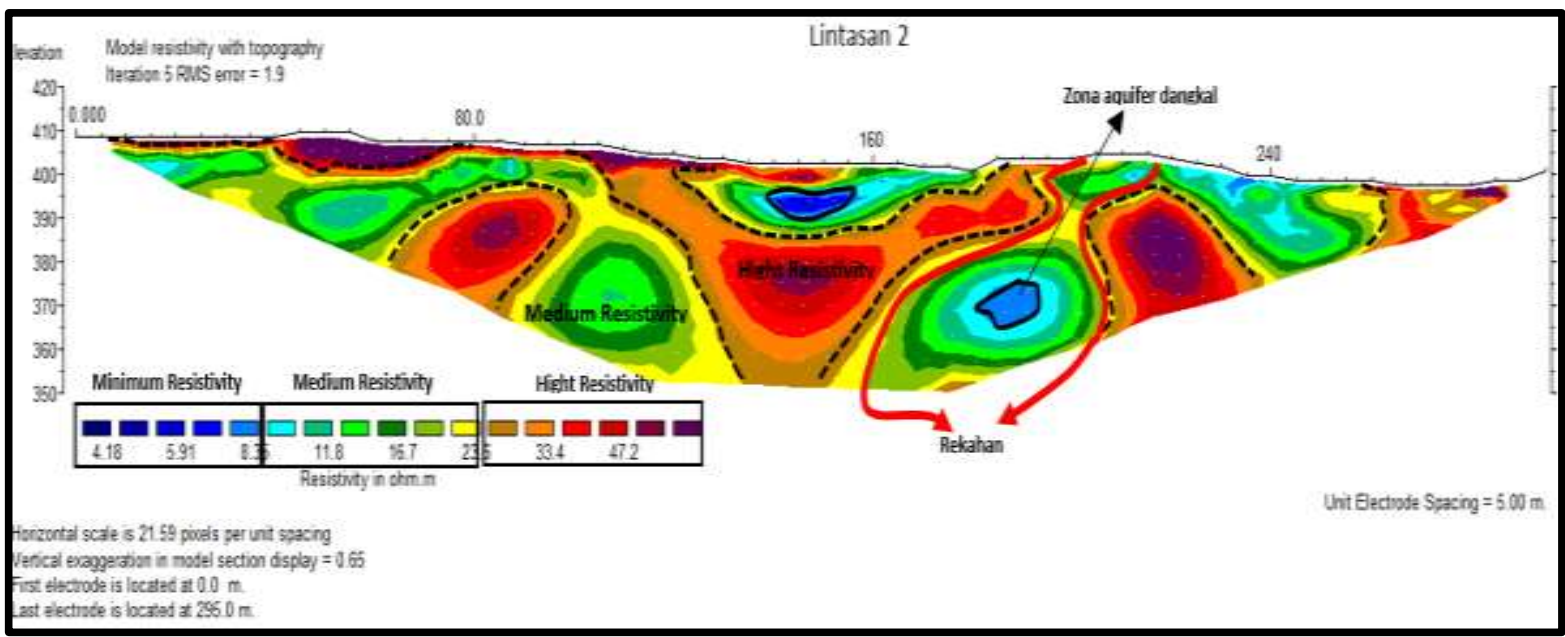

Gambar 5. Penampang resistivitas lintasan 2 


\section{Lintasan 3}

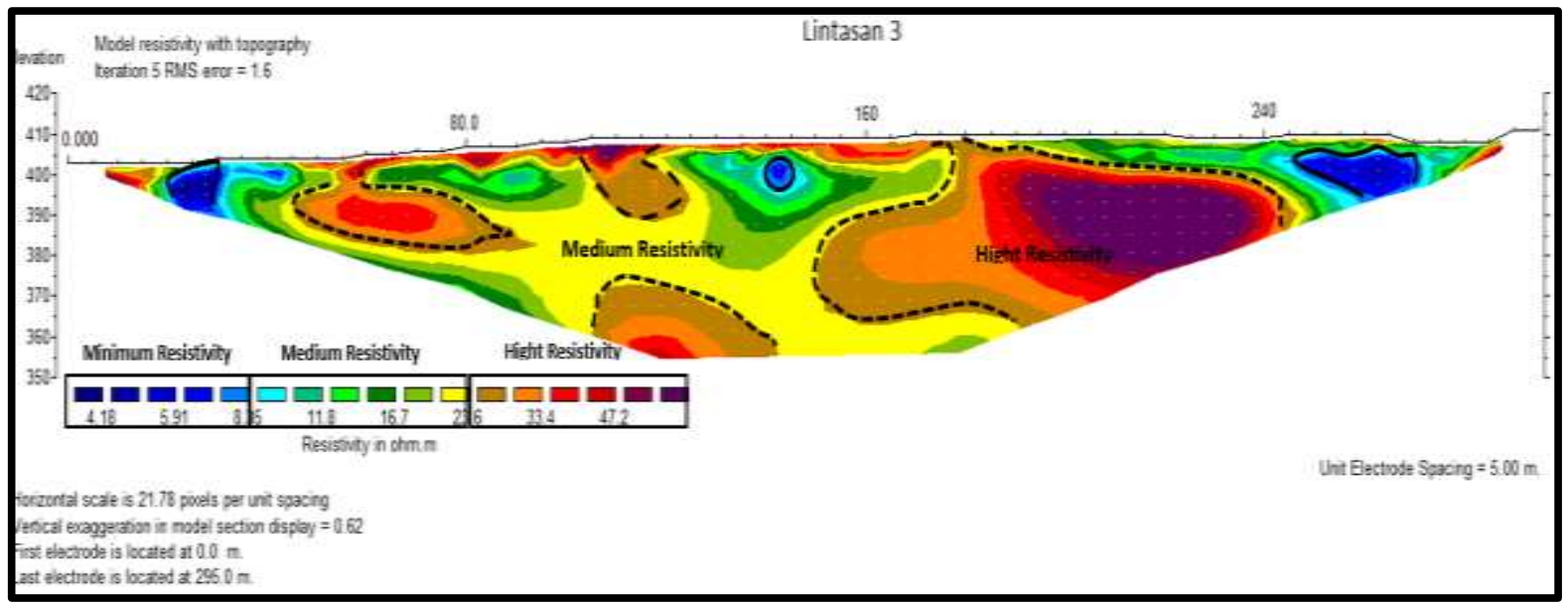

Gambar 6. Penampang resistivitas lintasan 3

Lintasan 4

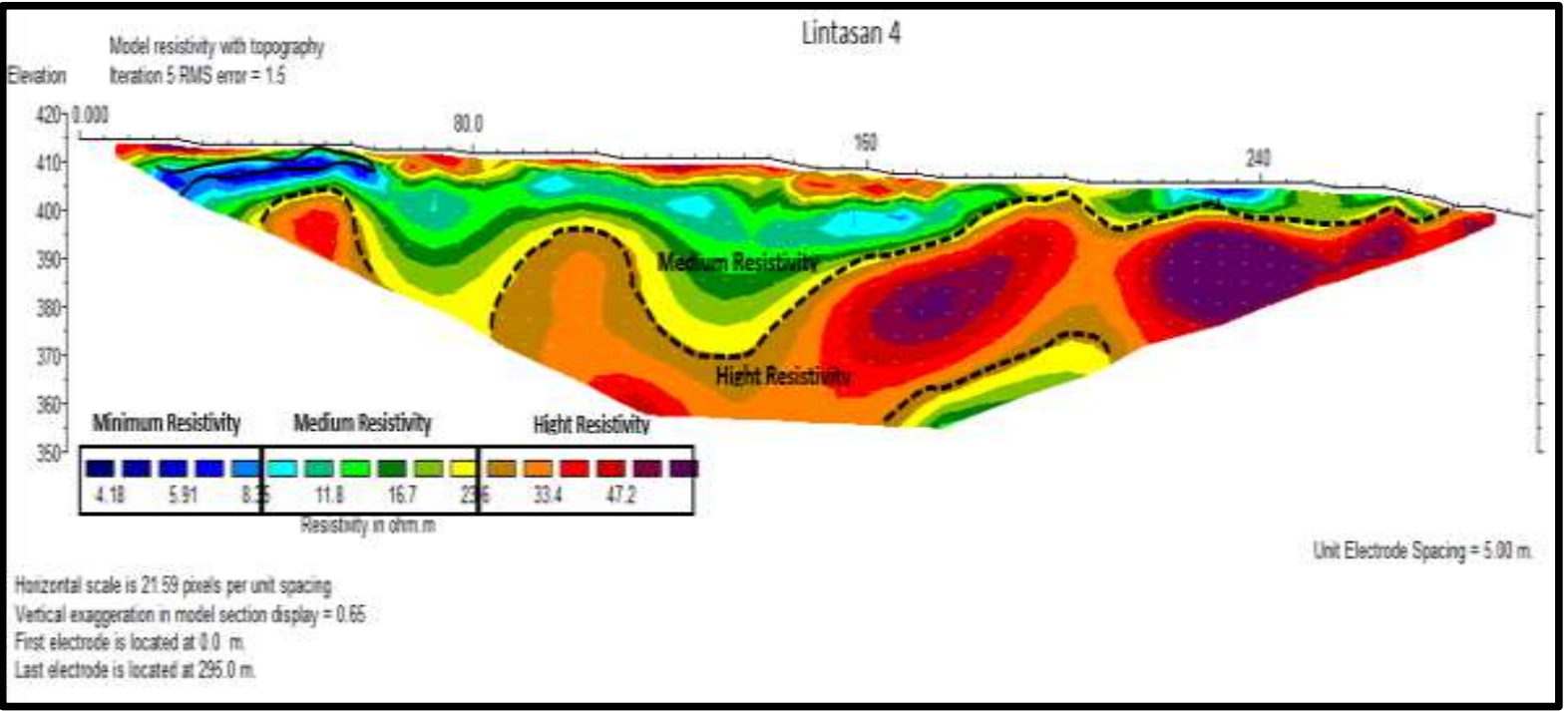

Gambar 7. Penampang resistivitas lintasan 4 


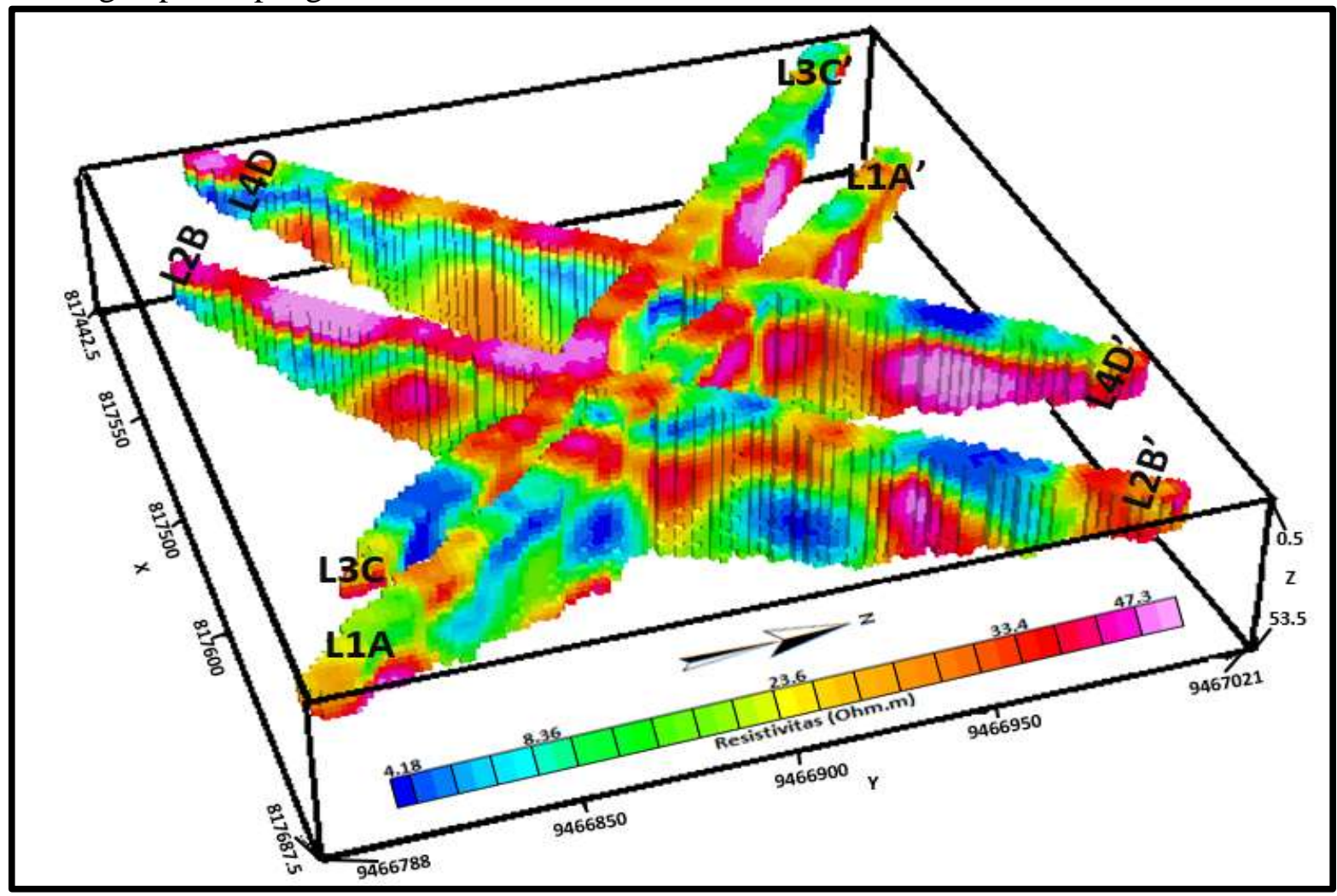

Gambar 8. Gabungan penampang resistivitas 2D daerah penelitian

Berdasarkan peta geologi daerah penelitian (Gambar 1), daerah penelitian terletak di antara Formasi Mallawa (Tem) yang merupakan batupasir, konglomerat, batulanau, batulempung dan napal, Formasi Tonasa (Temt) merupakan batu gamping koral pejal sebagian terhablurkan dan batuan gunungapi Formasi Camba (Tmcv) (Sukamto dan Supriatna, 1982). Hal ini dapat membantu dalam melakukan interpretasi data dengan mengkorelasikannya pada nilai resistivitas dan kondisi geologi di lapangan, yang merupakan sawah (lempung dan lanau) dan beberapa batuan yang ditemukan seperti batupasir, batugamping serta Sungai Walanae yang berada di bawah mata air panas Reatoa. Hal inilah yang menjadi dasar interpretasi pada penelitian ini sehingga diperoleh dugaan bahwa kondisi geologi bawah permukaan daerah penelitian adalah sebagai berikut:

1. Lintasan 1 (Gambar 4) membentang dari arah tenggara ke baratlaut sejauh $300 \mathrm{~m}$. Memiliki spasi elektroda terkecil 5 meter dengan kedalaman 52 meter dari permukaan. Lintasan ini menunjukkan kondisi bawah permukaan yang diduga berupa zona aquifer dangkal pada titik 110 - 130 m dan pada kedalaman 20 $40 \mathrm{~m}$ di bawah permukaan dengan nilai resistivitas masuk pada bagian low resistivity $(<8,35 \Omega \mathrm{m})$. Bagian medium resisitivity $(8,35 \Omega \mathrm{m}-16,7 \Omega \mathrm{m})$ diperkirakan sebagai satuan batupasir yang berselingan dengan batulempung dari Formasi Mallawa (Tem). Kemudian pada bagian high resistivity (> 23,6 $\Omega \mathrm{m}$ ) diperkirakan sebagai breksi gunungapi yang berasal dari batuan Gunungapi Formasi Camba (Tmcv).

2. Lintasan 2 (Gambar 5) memiliki arah bentangan dari baratdaya ke timurlaut yang memotong lintasan 1. Lintasan ini memiliki spasi elektroda dan panjang bentangan yang sama dengan lintasan 1 . Hasil analisis nilai resistivitas kondisi bawah permukaan diduga merupakan zona aquifer dangkal yang masuk ke dalam bagian low resistivity $(<8,35$ 
$\Omega \mathrm{m})$. Zona ini terletak pada titik $180-$ 200 m lintasan dan pada kedalaman 20 $40 \mathrm{~m}$ di bawah permukaan. Lapisan ini diduga merupakan kesinambungan dari zona lemah (rekahan) yang terlihat pada titik $210-215 \mathrm{~m}$, memiliki nilai resistivitas sama dengan zona aquifer dangkal yang sejajar dengan lokasi mata air panas. Pada bagian medium resisitivity $(8,35 \Omega \mathrm{m}-16,7 \Omega \mathrm{m})$ dan high resistivity (> 23,6 $\Omega \mathrm{m}$ ) memiliki interpretasi yang sama dengan lintasan 1.

3. Lintasan 3 (Gambar 6) membentang dari arah tenggara ke baratlaut sejajar dengan lintasan 1 yang memotong lintasan 2 . Pada lintasan 4 (Gambar 7) memiliki arah bentangan dari baratdaya ke timurlaut sejajar dengan lintasan 2 serta memotong lintasan 1 dan 3. Kedua lintasan ini memiliki panjang bentangan dan spasi elektroda yang sama dengan lintasan 1 dan 2. Interpretasi pada lintasan 3 sama dengan lintasan 4, hal ini karena pada bagian yang nilai resistivitasnya rendah atau masuk ke dalam low resistivity $(<\quad 8,35 \Omega \mathrm{m})$ diduga merupakan batulanau dengan sisipan batulempung dari Formasi Mallawa (Tem) yang telah berasosiasi dengan air karena pada titik ini merupakan daerah resapan dari sungai yang berada sekitar lokasi penelitian. Pada bagian medium resisitivity $(8,35$ $\Omega \mathrm{m}-16,7 \Omega \mathrm{m})$ diperkirakan sebagai satuan batupasir yang berselingan dengan batulempung dari Formasi Mallawa (Tem). Kemudian pada bagian high resistivity (> 23,6 $\Omega \mathrm{m}$ ) diperkirakan sebagai breksi gunungapi yang berasal dari batuan Gunungapi Formasi Camba (Tmcv).

4. Pada gabungan penampang 2D (Gambar 8) menunjukkan penampang gabungan resistivitas 2D. Berdasarkan gambar tersebut, diduga bahwa zona aquifer dangkal yang terdapat pada lintasan 1 merupakan satu kesatuan dengan zona aquifer yang terdapat pada lintasan 2 . Sehingga pada bagian ini ditafsirkan sebagai zona penyebaran hydrothermal.

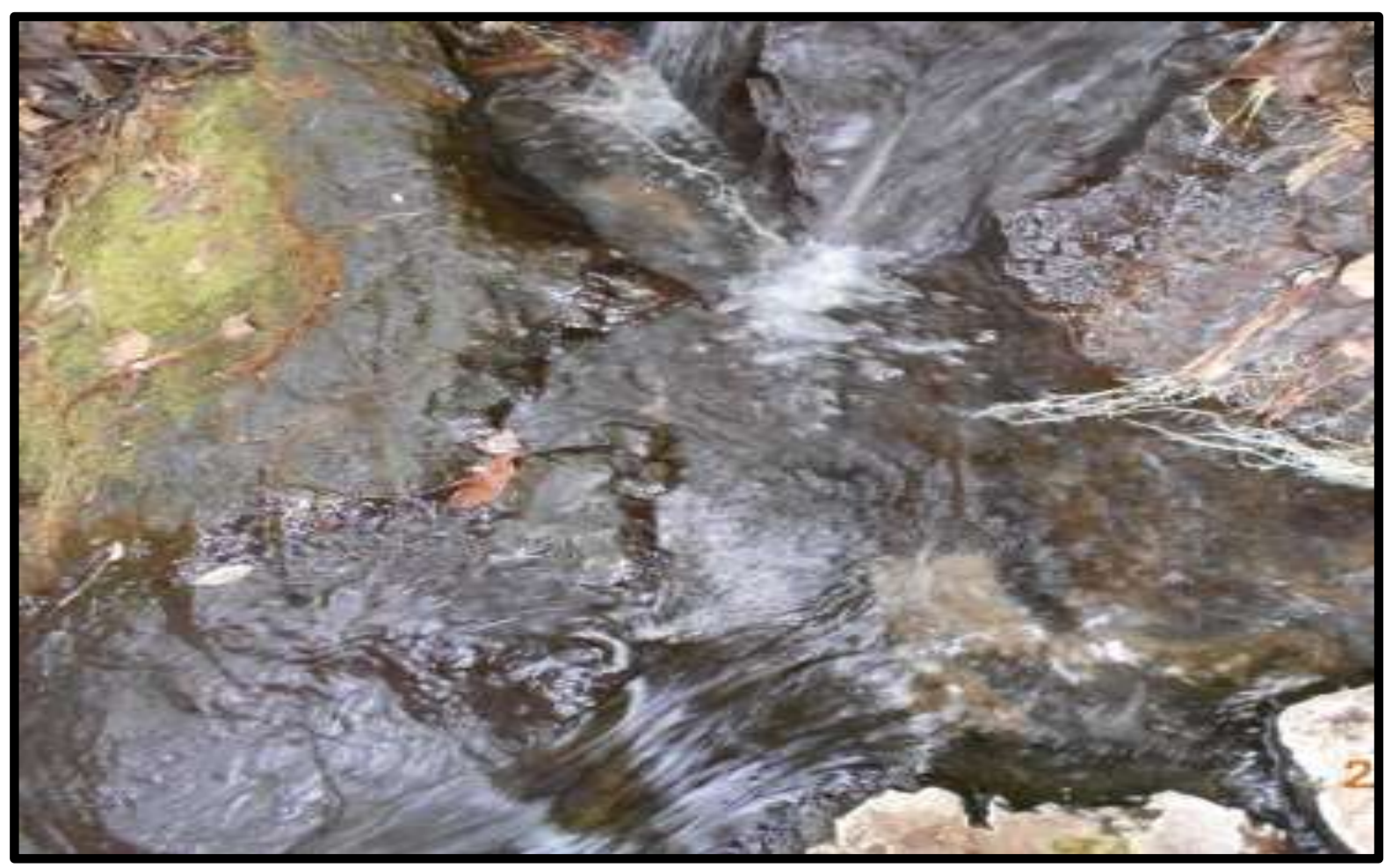

Gambar 9. Kenampakkan mata air panas Reatoa 


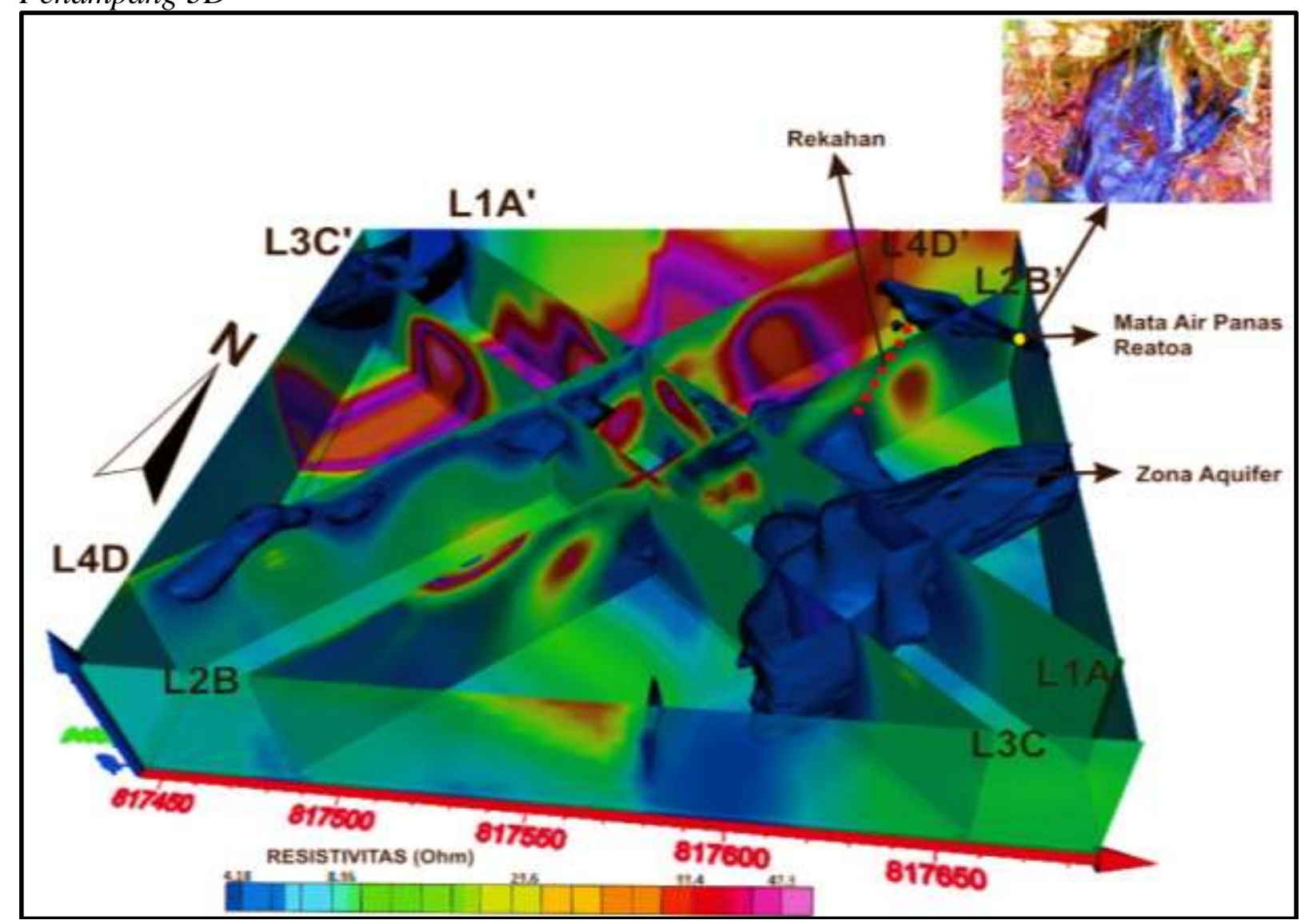

Gambar 10. Penampang resistivitas 3D daerah penelitian

Daerah penelitian berada pada jalur yang dilalui oleh Sesar Walanae yang melalui beberapa kabupaten di Sulawesi Selatan antara lain Pinrang, Gowa, Sinjai, Bulukumba dan Bone. Hal ini diperkuat oleh Hall dan Wilson (2000) pada dalam peta geologi Sulawesi. Daerah Mallawa terletak di bagian timur Kabupaten Maros yang berbatasan langsung dengan Kabupaten Bone yang dilalui oleh Sesar Walanae. Proses terbentuknya Sesar Walanae juga memberikan peranan dalam pembentukan sesar - sesar kecil di daerah sekitarnya (Sompotan, 2012). Hal inilah yang menjadi dasar interpretasi bahwa adanya rekahan di lokasi penelitian diakibatkan oleh proses terbentuknya Sesar Walanae yang juga membentuk struktur struktur geologi lain seperti rekahan di daerah sekitarnya termasuk daerah Mallawa.
Penampang resistivitas 3D (Gambar 10) memperlihatkan bahwa rekahan yang ditemukan pada titik 210 - $215 \mathrm{~m}$ di lintasan 2 memiliki arah yang sejajar dengan mata air panas Reatoa. Diduga rekahan tersebut merupakan jalur keluarnya fluida panas yang berasal dari zona aquifer pada lintasan 1 dan 2. Hal ini dibuktikan dengan mata air panas Reatoa yang keluar melalui rekahan pada batuan seperti yang terlihat pada (Gambar 9). Maka dapat disimpulkan bahwa munculnya manifestasi mata air panas Reatoa diduga terjadi akibat aktivitas tektonik oleh Sesar Walanae yang letaknya berada di dekat daerah penelitian.

\section{Kesimpulan}

Struktur geologi pada daerah penelitian diduga berupa rekahan, yang terlihat pada titik 110 - 130 m lintasan 1 dan 210 - 215 $\mathrm{m}$ di lintasan 2 serta memiliki arah yang sejajar dengan mata air panas Reatoa. Pada 
rekahan inilah fluida panas yang terdapat di zona aquifer memiliki celah ke permukaan. Hal ini dibuktikan dengan kondisi di lapangan yakni mata air panas Reatoa terlihat keluar melalui rekahan pada batuan.

Sistem hydrothermal yang muncul dari lapisan bawah permukaan diduga akibat Sesar Walanae yang pada saat terbentuknya juga membentuk struktur geologi lain di daerah sekitarnya termasuk daerah Mallawa. Salah satu struktur geologi tersebut berupa rekahan seperti yang ada pada daerah Mallawa, sehingga dapat dsimpulkan bahwa manifestasi mata air panas Reatoa terbentuk akibat aktivitas tektonik pada saat terbentuknya Sesar Walanae.

\section{Ucapan Terima Kasih}

Penulis mengucapkan terima kasih kepada seluruh pihak yang telah berkontribusi selama penelitian dilakukan. Terkhusus kepada pihak Departemen Geofisika Universitas Hasanuddin yang telah banyak membantu dalam penyusunan karya ilmiah ini.

\section{Daftar Pustaka}

Fais, Muhammad. 2017. Eksplorasi Mata Air Panas dengan Metode Geokimia dan Geolistrik Resistivitas Daerah Kabupaten Pinrang. Skripsi, Universitas Hasanuddin.

Hall, R. and Wilson, M. E. J. 2000, Neogene sutures in eastern Indonesia. Journal of Asian Earth Sciences 18 pp.781-808.

Lantu, Suriahmiharja. D.A, Imran A.M dan Harianto, Tri. 2015. Identifikasi Zona Akuifer Hidrotermal Menggunakan Metode Geolistrik Hambatan Jenis di Sekitar Sumber Air Panas Panggo Desa Kaloling Kabupaten Sinjai. Indonesian Journal of Applied Physics 5(2) pp.41-48.
Loke, M.H. 2004. Rapid 2D Resistivity \& IP Inversion using the least-square method, Geotomo Software. Malaysia.

Pusat Penelitian dan Pengembangan Geologi Bandung, 2010. Peta Geologi Regional Lembar Pangkajene dan Watampone Bagian Barat. Sulawesi lembar skala 1:250.000: Bandung

Saptadji, Nenny Miryani. 2001. Diktat Kuliah Teknik Eksploitasi Panasbumi. Bandung: Departemen Teknik Perminyakan ITB.

SAS Planet. 2014. Peta Lintasan Pengukuran Resistivitas, Desa Samaenre, Kecamatan Mallawa, Kabupaten Maros. Diakses pada 20 Desember 2019.

Sompotan, A.F. 2012. Struktur Geologi Sulawesi. Perpustakaan Sains dan Kebumian Institut Teknologi Bandung: Bandung.

Sukamto, Rab dan Supriatna. 1982. Geologi lembar Pangkajene dan Watampone bagian barat. Bandung: Puslitbang Geologi.

Telford, W.M., Geldart, L.P., \& Sherif, R.F. 1990. Applied Geophysics: Second Edition. Cambridge University Press: New York.

*) Artikel ini telah dipresentasikan di Seminar Nasional Geofisika 2019 yang dilaksakan oleh Dept. Geofisika FMIPA Universitas Hasanuddin di Science Building FMIPA Universitas Hasanuddin pada tanggal 26 Oktober 2019. 